\title{
Targeting of Basophil and Mast Cell Pro-Allergic Reactivity Using Functionalised Gold Nanoparticles
}

\author{
Inna M. Yasinska ${ }^{*}$, Luigi Calzolai², Ulrike Raap³, Rohanah Hussain ${ }^{4}$, Giuliano Siligardi", \\ Vadim V. Sumbayev ${ }^{1}$ and Bernhard F. Gibbs ${ }^{1,3 *}$ \\ ${ }^{1}$ Medway School of Pharmacy, Universities of Kent and Greenwich, Chatham Maritime, United Kingdom, ${ }^{2}$ European \\ Commission, Joint Research Centre, Ispra, Italy, ${ }^{3}$ Division of Experimental Allergology and Immunodermatology, University \\ of Oldenburg, Oldenburg, Germany, ${ }^{4}$ Beamline B23, Diamond Light Source, Didcot, United Kingdom
}

\section{OPEN ACCESS}

Edited by:

José das Neves,

Instituto de Investigação e Inovação

em Saúde, Portugal

Reviewed by:

Fiorentina Roviezzo,

University of Naples Federico II, Italy

Marco Aurélio Martins,

Fundação Oswaldo Cruz (Fiocruz),

Brazi

Glenn Cruse,

North Carolina State University,

United States

*Correspondence:

Inna M. Yasinska

I.Yasinska-24@kent.ac.uk

Bernhard F. Gibbs

bernhard.gibbs@uni-oldenburg.de

Specialty section:

This article was submitted to Experimental Pharmacology

and Drug Discovery,

a section of the journal

Frontiers in Pharmacology

Received: 07 December 2018 Accepted: 19 March 2019

Published: 29 March 2019

Citation:

Yasinska IM, Calzolai L, Raap U, Hussain R, Siligardi G, Sumbayev WV

and Gibbs BF (2019) Targeting of Basophil and Mast Cell Pro-Allergic Reactivity Using Functionalised Gold

Nanoparticles.

Front. Pharmacol. 10:333. doi: 10.3389/fphar.2019.00333
Calcineurin inhibitors potentially prevent pro-allergic mediator release from basophils and mast cells but are rarely used systemically due to ubiquitous expressions of target signaling proteins. However, specific targeting of allergic effector cells with these inhibitors could circumvent unwanted side effects. We recently demonstrated the biocompatibility of gold nanoparticles (AuNPs) as a platform for non-toxic delivery of signaling inhibitors due to unique physicochemical properties of these nanomaterials. Since AuNPs can be conjugated with both anti-allergic drugs and antibodies or other proteins that specifically recognize basophils and mast cells, our aims were to assess specific targeting of allergic effector cell function using AuNPs conjugated with the calcineurin inhibitor ascomycin. Purified human basophils and LAD2 human mast cells were used for investigations with AuNPs conjugated either to CD203c antibodies or containing stem cell factor (SCF), respectively, which were amine-coupled to acidic groups of reduced glutathione (GSH). GSH was also used as a spacer for immobilization of ascomycin on the gold surface. AuNPs conjugated with anti-CD203c and ascomycin strikingly blocked IgE-dependent degranulation of both purified basophils and those present in mixed leukocyte preparations, suggesting specific targeting of these cells. In contrast, LAD2 mast cell responses were not inhibited using anti-CD203c-containing nanoconjugates but were when the conjugates contained SCF. Successful targeting of allergic effector cells using gold nanoconjugates indicates that this technology may have therapeutic potential for the treatment of allergies by specifically delivering highly effective signaling inhibitors with reduced side effects.

Keywords: gold nanoconjugates, basophils, mast cells, ascomycin, IgE, CD203c, stem cell factor

\section{INTRODUCTION}

Inflammatory mediator release, (e.g., histamine) from basophils and mast cells plays a major role in contributing to the symptoms of allergic reactions and these cells may also support the underlying tendency for an individual's immune system to respond in a pro-allergic manner (reviewed in Varricchi et al., 2018). In terms of anti-allergic therapy, it is therefore desirable to target these cells and limit their ability to release inflammatory and immunomodulatory 
mediators. Several pharmacological inhibitors of intracellular signaling, (e.g., Syk and calcineurin inhibitors) have been shown to substantially reduce the ability of mast cells and basophils to release allergic mediators following stimulation of the highaffinity IgE receptor (FceRI) (Oliver et al., 1994; Zuberbier et al., 2001; Plath et al., 2003; Matsubara et al., 2006; Rossi et al., 2006; Harrison et al., 2007). However, due to the ubiquitous expressions of intracellular signals systemic clinical use of these inhibitors is problematical in terms of potential side effects and adverse drug reactions. It is therefore desirable to be able to specifically target effector cells involved in human allergy with drugs that are known to prevent allergen-induced cell activation and the release of pro-inflammatory mediators.

We recently reported the proof-of-principle that gold nanoparticles (AuNPs) could be used to specifically target basophils and other cell types with certain signal transduction inhibitors (Gibbs et al., 2014; Yasinska et al., 2018). Furthermore, compared to most other nanomaterials, AuNPs are relatively non-toxic (Deng et al., 2011; Pissuwan et al., 2011) and are easily conjugated with pharmacological agents and antibodies/antigenbinding peptides (Ma et al., 2010; Gibbs et al., 2014; Yasinska et al., 2018). Moreover, we observed that AuNPs display inherent antiinflammatory properties themselves by neutralizing the effects of IL-1 $\beta$ (Sumbayev et al., 2013), a cytokine that contributes to allergic inflammation, particularly in asthma.

As a specific marker for mast cells and basophils, we chose CD203c [the ectonucleotide pyrophosphatase/phosphodiesterase family member 3 (ENPP-3)] since it is currently the only known membrane-associated protein that is almost exclusively expressed on both human mast cells and basophils (Bühring et al., 2001; Ghannadan et al., 2002). This marker has been employed in flow cytometric assays for clinical diagnostics regarding basophil activation (Boumiza et al., 2003; Kleine-Tebbe et al., 2006). Its biological function in these cells is not clear but its surface expression is upregulated by priming factors involved in allergic diseases, such as IL-3, and during allergic responses of these cells (Hauswirth et al., 2007; Ono et al., 2010).

Given the above statements, our main aim was to specifically target and inhibit the function of primary human basophils and LAD2 mast cells using AuNPs conjugated to anti-CD203c and ascomycin. Furthermore, we characterized our AuNPbased nanoconjugates (NCJ) using synchrotron radiation circular dichroism (SRCD) spectroscopy. We also compared the effects of NCJ containing anti-CD203c to those conjugated to stem cell factor (SCF). This may allow mast cell-selective targeting since SCF binds to KIT, a receptor that is highly expressed in mature mast cells (other cells include immature haemopoietic stem cells, melanocytes and interstitial cells of the Cajal).

\section{METHODS}

\section{Generation and Characterization of NCJ}

Synthesis of $5 \mathrm{~nm}$ AuNPs was performed essentially as described previously (Sumbayev et al., 2013; Gibbs et al., 2014; Yasinska et al., 2018). Briefly, $5 \mathrm{ml}$ of aqueous gold (III) chloride trihydrate $(10 \mathrm{mM})$ and $2.5 \mathrm{ml}$ of aqueous sodium citrate $(100 \mathrm{mM})$ were added to $95 \mathrm{ml}$ of milliQ-water in a round bottom flask equipped with a magnetic stirrer. The solution (which has a pale yellow appearance) was cooled down to $1-2^{\circ} \mathrm{C}$. Under vigorous stirring $1 \mathrm{ml}$ of aqueous sodium borohydride $\left(4^{\circ} \mathrm{C}\right.$, $0.1 \mathrm{M}$ ) was added and the solution (which should have a dark red appearance) was then stirred for further $10 \mathrm{~min}$ on an ice bath before being allowed to warm up to room temperature. NCJ were generated as described before using glutathione as a linker to immobilize one molecule of antiCD203c antibody or SCF per 1 nanoparticle. The rest of the surface was covered by glutathiolated (through $-\mathrm{COOH}$ group) ascomycin (maximum 1,000 molecules per nanoparticle) (Gibbs et al., 2014; Yasinska et al., 2018). The same principle was adopted for the generation of SCF-containing NCJ (where SCF was employed instead of anti-CD203c). Nanomaterials were characterized using SRCD spectroscopy as described previously (Yasinska et al., 2018).

Briefly, SRCD measurements were conducted using $10 \mathrm{~cm}$ path length cell with $3 \mathrm{~mm}$ aperture diameter and capacity of $800 \mu \mathrm{l}$ using the Module B with a $1 \mathrm{~nm}$ increment, $1 \mathrm{~s}$ integration time and $1.2 \mathrm{~nm}$ bandwidth at $23^{\circ} \mathrm{C}$ (Hussain et al., 2012; Yasinska et al., 2018). The results obtained were analyzed using CDAPPs program (Hussain et al., 2012, 2015) and Origin software (OriginLab $\left.{ }^{\mathrm{TM}}\right)$.

\section{Basophil Isolation and Purification}

Basophils, were isolated from buffy coat blood (purchased from the NHS Blood and Transplant service following ethics approval (NHS REC 12/WM/0319) by Ficoll-density centrifugation and purified further (to $>90 \%$ ) by immunomagnetic cell sorting using commercial kits, as previously described (Gibbs et al., 2008). Basophil purities were determined by alcian blue staining.

\section{LAD2 Mast Cells}

LAD2 cells were generously provided to us by Dr. A. Kirshenbaum and Prof. D. Metcalfe (NIH, Bethesda, United States) and cultured in Stem-Pro-34 serum-free media in the presence of $100 \mathrm{ng} / \mathrm{ml} \mathrm{SCF}$ as previously reported (Kirshenbaum et al., 2003). Human SCF protein was produced in Escherichia Coli and purified following established protocols (Wang et al., 2008). Cells were sensitized with $100 \mathrm{ng} / \mathrm{ml}$ polyclonal IgE (Amsbio, Abingdon, United Kingdom) $24 \mathrm{~h}$ before the experiments.

\section{Cell Stimulation and Histamine Release Assay}

Cells were re-suspended in HEPES-buffered Tyrode's solution (containing $1 \mathrm{mM} \mathrm{CaCl}_{2}$ ) and pre-incubated with or without either NCJ or ascomycin alone (5 or $100 \mathrm{nM}$ ) for $15 \mathrm{~min}$ at $37^{\circ}$ before stimulation (either anti-IgE $(1 \mu \mathrm{g} / \mathrm{ml})$, fMLP $(100 \mathrm{nM})$ or buffer alone) for $30 \mathrm{~min}$. Following centrifugation, histamine content were determined in the supernatants and lysed cell pellets by spectrofluorometric analysis based on the method described by Shore et al. (1959). Histamine releases were calculated by dividing histamine content in respective supernatants by that present in equivalent cell lysates $\times 100 \%$. 
Net histamine releases were then calculated by subtracting spontaneous secretions and the results then presented as percentage inhibitions of net histamine release caused by the stimulus alone.

\section{Statistical Analysis}

Each experiment was performed at least three times. When comparing two events at a time we used a two-tailed Student's $t$-test. Multiple comparisons were performed by ANOVA test and post hoc Bonferroni correction was applied. Statistical probabilities $(\mathrm{p})$ were shown in the figures as ${ }^{*}$ for $p<0.05$; ** for $p<0.01$ and $* * *$ for $p<0.001$.

\section{RESULTS}

Our first objective was to characterize the NCJs using far-UV CD spectra of the components, the materials and compounds comprising the anti-CD203c- and ascomycin-conjugated AuNPs (Figures 1A-F) by use of SRCD spectroscopy (Figure 1G). Our observations confirmed that immobilization of both antibody and the drug was successful.

Next, we compared the effects of NCJs and ascomycin alone on histamine release from purified human basophils stimulated either with anti-IgE (Figures 2A,B and Supplementary Figures 1A,B) or the N-formylated tripeptide fMLP (Figure 2C and Supplementary Figures 1C,D). In agreement with our previous observations (Gibbs et al., 2014) NCJs containing ascomycin and anti-CD203c substantially inhibited IgEdependent basophil histamine release and this level of inhibition was similar to that seen with $100 \mathrm{nM}$ ascomycin alone. Our current results also include the effects of NCJs without ascomycin, which did not show any inhibitory properties. In contrast, NCJs were less effective at inhibiting histamine release from basophils induced by fMLP, although the inhibitory effects with NCJs were still significantly greater than those seen with ascomycin alone at the highest concentration (Figure 2C).

We next asked whether the striking inhibitory properties of NCJs regarding the abrogation of IgE-dependent histamine release from purified basophils were matched in unpurified basophil preparations. Indeed, NCJs had similar inhibitory effects in both preps, while ascomycin alone was less effective (especially at the lower, $5 \mathrm{nM}$, concentration), presumably due to specific basophil targeting by the NCJs and greater distribution of the free drug between basophils and contaminating peripheral blood mononuclear cells (Figure 2D and Supplementary Figure 2).

Surprisingly, NCJs containing anti-CD203c were not effective at inhibiting anti-IgE-induced histamine release from LAD2 mast cells (Figures 2E,F and Supplementary Figure 3). The effects of ascomycin alone were also less effective than previously observed for basophils, possibly owing to requiring longer preincubation periods than for basophils. Non-etheless, anti-CD203c-containing NCJ were even less effective at inhibiting histamine release from LAD2 mast cells than the moderate inhibition seen with ascomycin alone. In contrast, when coupled to SCF, the inhibitory actions of NCJ were restored to levels greater than seen for ascomycin alone. We also observed that SCF-containing NCJs were moderately (though significantly) effective at inhibiting basophilderived histamine release, though the inhibitory properties were considerably less compared to anti-CD203c-containing NCJs (Figure 2G).

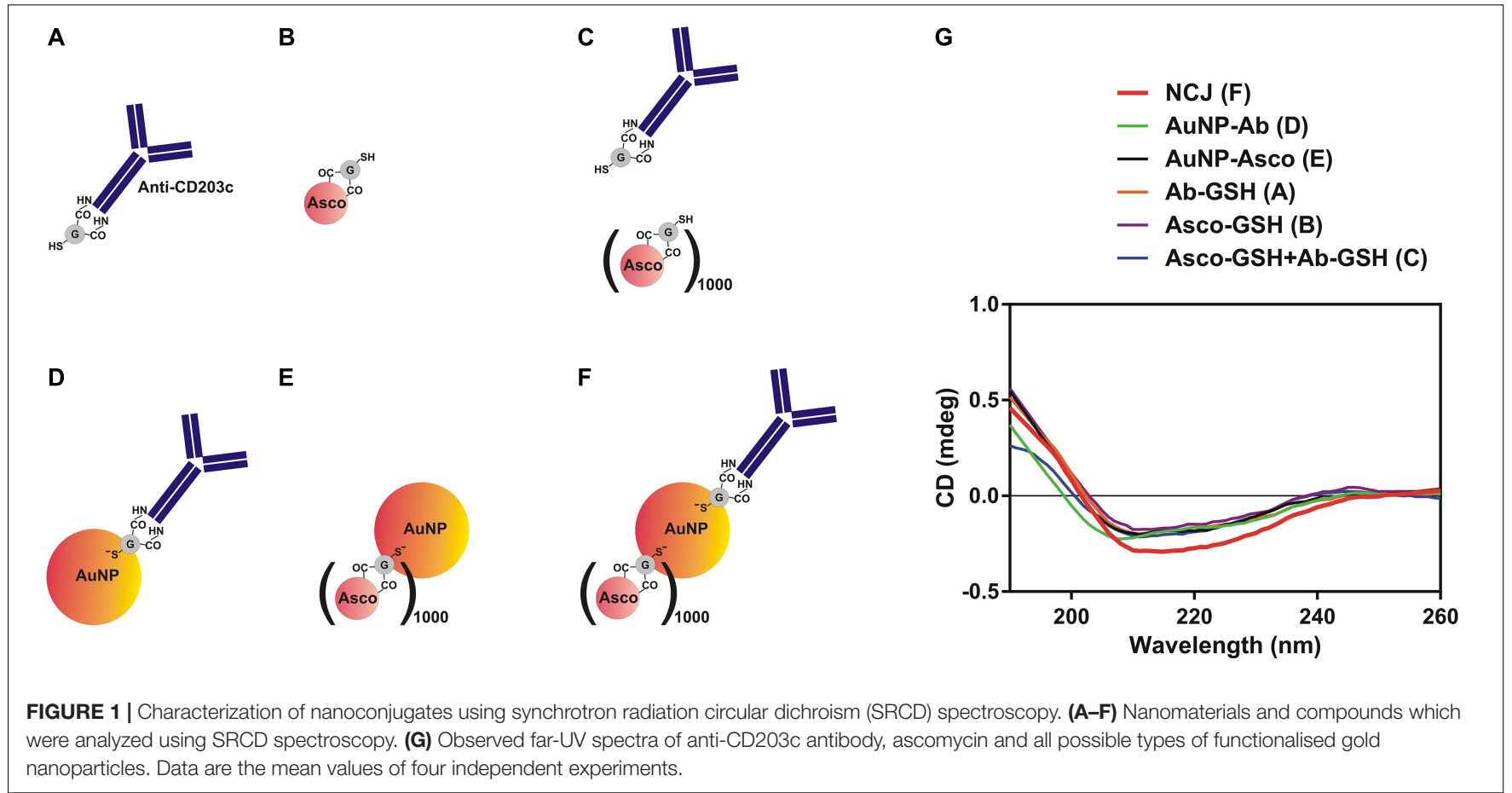


A

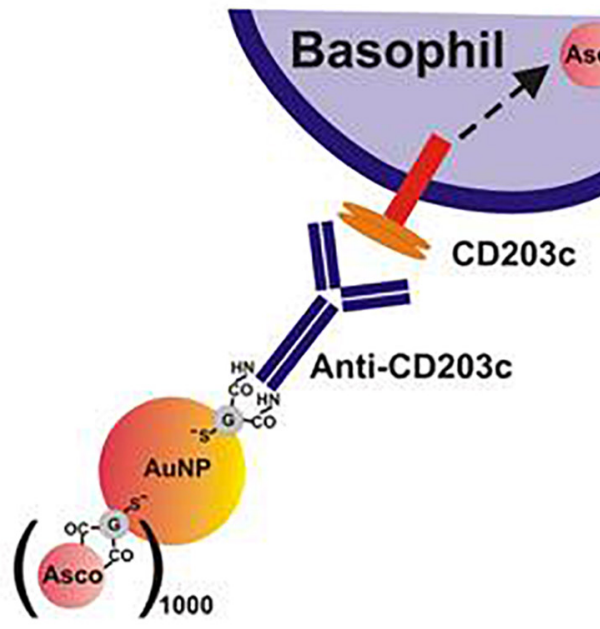

C

Basophils, stimulus - fMLP

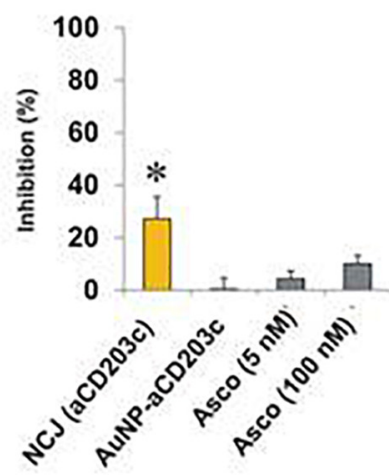

B

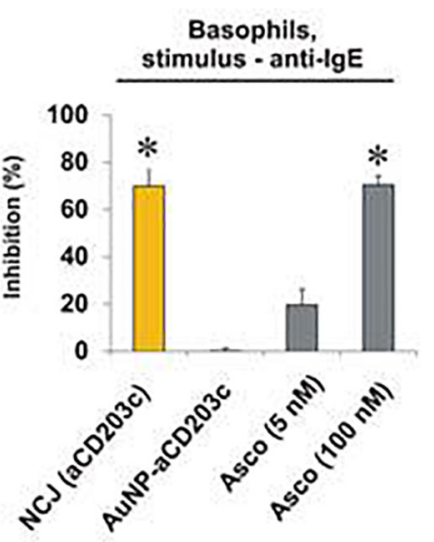

D

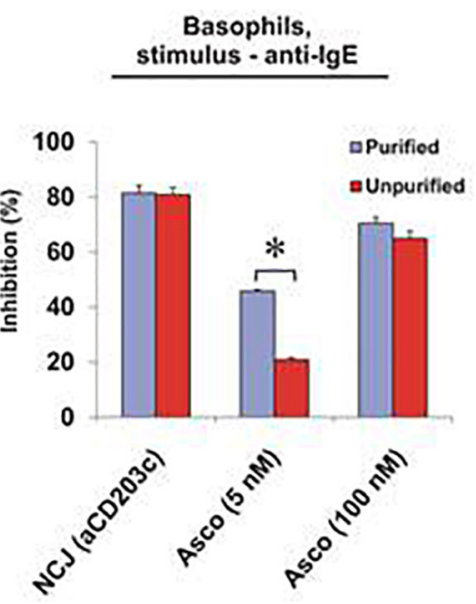

G
E

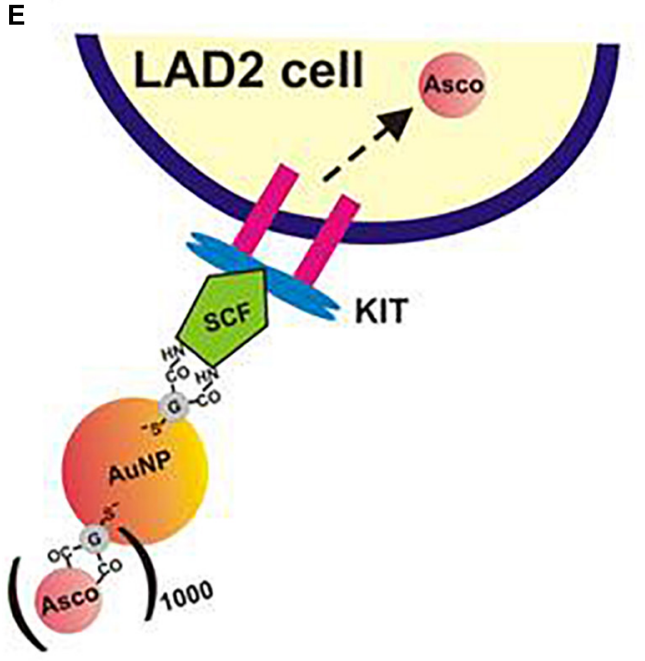

$\mathbf{F}$

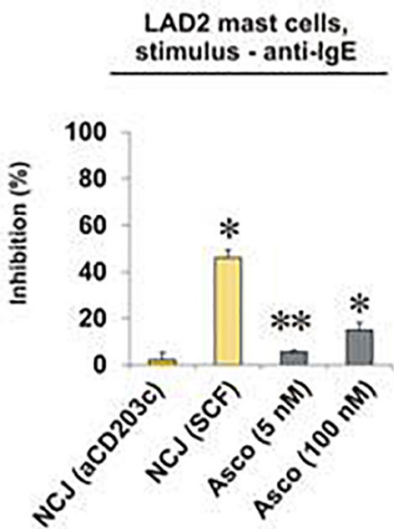

Basophils, stimulus - anti-lgE

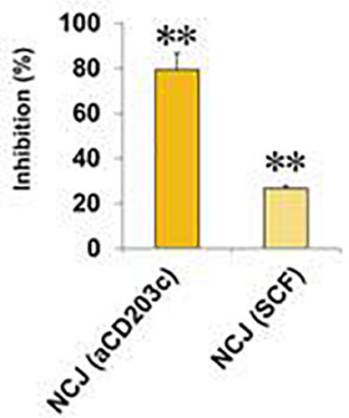


FIGURE 2 | Effect of NCJs on histamine release from human basophils and LAD2 mast cells. Cells were preincubated for 15 min either with NCJs, ascomycin or buffer alone before stimulation for $30 \mathrm{~min}$, after which histamine releases were assessed. All results are shown as percentage inhibition of histamine release \pm SEM. * and ** denote significant differences from control using a paired Student's $t$-test $(p<0.05$ or $p<0.01$, respectively). Panel A Scheme illustrating the interaction of a NCJ containing anti-CD203c with a human basophil and subsequent ascomycin delivery. Panel B Basophils stimulated with anti-lgE ( $n=4)$. Results were first corrected from spontaneous releases (5.4 $\pm 1.1 \%)$ and percentage inhibition calculated from net anti-IgE-induced release in the absence of NCJs or inhibitors $(25.3 \pm 4.1 \%)$. Panel C Basophils stimulated with $\mathrm{fMLP}(n=4)$. Results were first corrected from spontaneous releases $(4.2 \pm 1.2 \%)$ and percentage inhibition calculated from net fMLP-induced release in the absence of NCJs or inhibitors (31.6 $\pm 4.0 \%)$. Panel D Comparison of the inhibitory effects of NCJs and ascomycin alone in purified (>90\% pure) and unpurified (<2\% pure) human basophils stimulated with anti-IgE. Spontaneous histamine releases ( $4.6 \pm 0.5 \%$ for purified basophils, $3.2 \pm 0.7 \%$ for unpurified basophils) were first subtracted and the results expressed as percentage inhibition of histamine release caused by anti-lgE alone (net releases were $14 \pm 2.7 \%$ for purified basophils, $14.2 \pm 2.5 \%$ for unpurified basophils) $(n=8)$. Panel $\mathbf{E}$ Scheme illustrating interaction of a NCJ containing SCF with LAD2 mast cell and subsequent ascomycin delivery. Panel F Effect of NJCs on histamine release from LAD2 cells stimulated with anti-lgE ( $n=6$ ). Results were first corrected from spontaneous releases (15.7 $\pm 0.5 \%)$ and percentage inhibition calculated from net anti-lgE-induced release in the absence of NCJs or inhibitors (15.9 $\pm 0.7 \%$ ). Panel G Effect of different NJCs on histamine release from purified human basophils stimulated with anti-IgE. Results were first corrected from spontaneous releases ( $4.0 \pm 0.3 \%)$ and percentage inhibition calculated from net anti-lgE-induced release in the absence of NCJs or inhibitors (10.6 $\pm 1.0 \%$ ).

\section{DISCUSSION}

Our SRCD spectroscopy results demonstrate that immobilization of ascomycin and anti-CD203c on the gold surface of AuNPs doesn't affect the antibody secondary structure, based on unchanged shape of the respective SRCD spectrum curves (Figure 1G; successful immobilizations of targeting agents on AuNPs is shown in Supplementary Figure 4). This explains preserved biochemical activity of the antibody upon its immobilization on the gold surface. This is confirmed by the functional activities of the NCJs in terms of targeting and inhibiting histamine release from allergic effector cells. For basophils, this inhibitory action was clearly due to the presence of ascomycin on the NCJs, since no effects were observed using NCJs without ascomycin conjugation. Furthermore, the inhibitory actions of ascomycin were more pronounced in terms of inhibiting IgE-dependent histamine release compared to fMLP. As a result, ascomycin-containing NCJs were also less effective at inhibiting fMLP-induced basophil histamine release.

The concentration of ascomycin delivered into basophils within the NCJs was maximally $5 \mathrm{nM}$, based on stoicheometrical calculations on the number of ascomycin molecules fused to each nanoparticle and the number of nanoparticles incubated with basophils (Gibbs et al., 2014). The increased inhibitory effect of these NCJs compared to incubation with $5 \mathrm{nM}$ ascomycin alone supports that the NCJs facilitate specific cellular targeting. Furthermore, we obtained the same results with the NCJs in both pure and unpure basophils preparations, whereas $5 \mathrm{nM}$ ascomycin alone displayed less inhibitory effects on unpure basophils than pure basophils. This suggests that ascomycin, which is a relatively lipophilic molecule, would otherwise disperse into various cell populations in vivo, lowering its effective concentration in basophils and increasing the likelihood of side effects (thus emphasizing the need for cell-specific targeting using NCJs).

In terms of the effects of NCJs on LAD2 mast cells, antiCD203c conjugation surprisingly failed to target these cells, where no significant inhibition of IgE-dependent histamine release was observed in contrast to ascomycin alone. Indeed, we observed that LAD2 cells expressed barely detectable levels of CD203c (Supplementary Figure 5A). This suggests that CD203c may be absent in certain aberrant mast cell disorders although it is be widely expressed both on a variety of human primary mast cells as well as in vitro cultured mast cells and other human mast cell lines (Ghannadan et al., 2002; Andersen et al., 2008; Cop et al., 2017). The LAD2 cell line is derived from a patient with mast cell leukemia/sarcoma (Kirshenbaum et al., 2003). However, neoplastic mast cells from systemic mastocytosis patients have, in contrast to our observations with LAD2 cells, been shown to overexpress CD203c (Hauswirth et al., 2008). This would advocate the use of NCJs containing anti-CD203c (or single chain antibodies/peptides against this protein) to target most other human mast cells and highlights the limitations of LAD2 mast cells in these particular studies.

An alternative mast cell-specific marker is CD117 (KIT), which binds SCF. Our results clearly showed, in contrast to anti-CD203c-containing NCJs, that NCJs containing SCF significantly inhibited LAD2 cell histamine release much more than ascomycin alone. This verifies the concept of specific drug delivery into mast cells using NCJs and shows that CD117 could be used to specifically target mast cells in tissues where other KIT-positive cells (present mainly in the bone marrow) are absent. We assumed that basophils could not be targeted with SCF-containing NCJs since, other than during development, they are generally considered to be CD117/KIT negative (Han et al., 2008). Indeed, Western blot analysis of LAD2 and basophil lysates clearly demonstrated high KIT expression in LAD2 mast cells whereas it was undetectable in basophils (Supplementary Figure 5B). However, SCF-containing NCJs still gave rise to a moderate inhibition of histamine release from basophils. This suggests that SCF may non-specifically interact with some of the basophil cell surface-based receptors or have a moderate affinity to some of them. The second scenario is more likely given that SCF is known to stimulate chemotaxis and the survival of peripheral blood basophils (Heinemann et al., 2005).

We conclude that AuNP-based NCJs are highly effective both at targeting human allergic effector cells and substantially 
blocking their function by delivering anti-allergic agents. However, expensive stability as well as in vivo safety testing will need to be conducted in before this technology can be developed further as a new therapeutic approach in a clinical setting.

\section{DATA AVAILABILITY}

The datasets generated for this study are available on request to the corresponding author.

\section{AUTHOR CONTRIBUTIONS}

BG conceived the work, together with VS, and conducted the experiments on basophils and LAD2 mast cells together with IY. LC provided and characterized the gold nanoparticles. VS, IY, and BG designed the nanoconjugates. RH, GS, IY, and VS characterized the NCJs using SRCD spectroscopy. UR contributed to analysis and interpretation of the data and critical

\section{REFERENCES}

Andersen, H. B., Holm, M., Hetland, T. E., Dahl, C., Junker, S., Schiøtz, P. O., et al. (2008). Comparison of short term in vitro cultured human mast cells from different progenitors - peripheral blood-derived progenitors generate highly mature and functional mast cells. J. Immunol. Methods 336, 166-174. doi: 10.1016/j.jim.2008.04.016

Boumiza, R., Monneret, G., Forissier, M. F., Savoye, J., Gutowski, M. C., Powell, W. S., et al. (2003). Marked improvement of the basophil activation test by detecting CD203c instead of CD63. Clin. Exp. Allergy 33, 259-265. doi: 10.1046/ j.1365-2222.2003.01594.x

Bühring, H. J., Seiffert, M., Giesert, C., Marxer, A., Kanz, L., Valent, P., et al. (2001). The basophil activation marker defined by antibody 97A6 is identical to the ectonucleotide pyrophosphatase/phosphodiesterase 3. Blood 97, 3303-3305. doi: 10.1182/blood.V97.10.3303

Cop, N., Decuyper, I. I., Faber, M. A., Sabato, V., Bridts, C. H., Hagendorens, M. M., et al. (2017). Phenotypic and functional characterization of in vitro cultured human mast cells. Cytometry B Clin. Cytom. 92, 348-354. doi: 10.1002/cyto.b. 21399

Deng, Z. J., Liang, M., Monteiro, M., Toth, I., and Minchin, R. F. (2011). Nanoparticle-induced unfolding of fibrinogen promotes Mac-1 receptor activation and inflammation. Nat. Nanotechnol. 6, 39-44. doi: 10.1038/nnano. 2010.250

Ghannadan, M., Hauswirth, A. W., Schernthaner, G. H., Müller, M. R., Klepetko, W., Schatzl, G., et al. (2002). Detection of novel CD antigens on the surface of human mast cells and basophils. Int. Arch. Allergy Immunol. 127, 299-307. doi: 10.1159/000057747

Gibbs, B. F., Papenfuss, K., and Falcone, F. H. (2008). A rapid two-step procedure for the purification of human peripheral blood basophils to near homogeneity. Clin. Exp. Allergy 38, 480-485. doi: 10.1111/j.1365-2222.2007.02919.x

Gibbs, B. F., Yasinska, I. M., Calzolai, L., Gilliland, D., and Sumbayev, V. V. (2014). Highly specific targeting of human leukocytes using gold nanoparticlebased biologically active conjugates. J. Biomed. Nanotechnol. 10, 1259-1266. doi: 10.1166/jbn.2014.1807

Han, X., Jorgensen, J. L., Brahmandam, A., Schlette, E., Huh, Y. O., Shi, Y., et al. (2008). Immunophenotypic study of basophils by multiparameter flow cytometry. Arch. Pathol. Lab. Med. 132, 813-819. doi: 10.1043/154321652008132

Harrison, C. A., Bastan, R., Peirce, M. J., Munday, M. R., and Peachell, P. T. (2007). Role of calcineurin in the regulation of human lung mast cell and evaluation of the manuscript content. All authors contributed to writing the manuscript.

\section{ACKNOWLEDGMENTS}

We would like to thank the Daphne Jackson Trust for providing a research fellowship to IY to support her contribution to this study. We are grateful to Diamond Light Source for providing access to B23 beamline (SM12578). We also thank Dr. Luca Varani (Institute for Research in Biomedicine, Bellinzona, Switzerland) for generously providing us with purified SCF. We also thank Dr. A. Kirshenbaum and Prof. D. Metcalfe (NIH, Bethesda, MD, United States) for kindly providing us with LAD2 cells.

\section{SUPPLEMENTARY MATERIAL}

The Supplementary Material for this article can be found online at: https://www.frontiersin.org/articles/10.3389/fphar. 2019.00333/full\#supplementary-material

basophil function by cyclosporine and FK506. Br. J. Pharmacol. 150, 509-518. doi: 10.1038/sj.bjp.0707002

Hauswirth, A. W., Escribano, L., Prados, A., Nuñez, R., Mirkina, I., Kneidinger, M., et al. (2008). CD203c is overexpressed on neoplastic mast cells in systemic mastocytosis and is upregulated upon IgE receptor cross-linking. Int. J. Immunopathol. Pharmacol. 21, 797-806. doi: 10.1177/039463200802 100404

Hauswirth, A. W., Sonneck, K., Florian, S., Krauth, M. T., Bohm, A., Sperr, W. R., et al. (2007). Interleukin-3 promotes the expression of E-NPP3/CD203C on human blood basophils in healthy subjects and in patients with birch pollen allergy. Int. J. Immunopathol. Pharmacol. 20, 267-278. doi: 10.1177/ 039463200702000207

Heinemann, A., Sturm, G. J., Ofner, M., Sturm, E. M., Weller, C., Peskar, B. A., et al. (2005). Stem cell factor stimulates the chemotaxis, integrin upregulation, and survival of human basophils. J. Allergy Clin. Immunol. 116, 820-826. doi: 10.1016/j.jaci.2005.06.008

Hussain, R., Benning, K., Javorfi, T., Longo, E., Rudd, T. R., Pulford, B., et al. (2015). CDApps: integrated software for experimental planning and data processing at beamline B23, Diamond Light Source. J. Synchrotron Radiat. 22, 465-468. doi: $10.1107 / \mathrm{S} 1600577514028161$

Hussain, R., Javorfi, T., and Siligardi, G. (2012). Circular dichroism beamline B23 at the diamond light source. J. Synchrotron Radiat. 19, 132-135. doi: 10.1107/ S0909049511038982

Kirshenbaum, A. S., Akin, C., Wu, Y., Rottem, M., Goff, J. P., Beaven, M. A., et al. (2003). Characterization of novel stem cell factor responsive human mast cell lines LAD 1 and 2 established from a patient with mast cell sarcoma/leukemia; activation following aggregation of FcepsilonRI or FcgammaRI. Leuk. Res. 27, 677-682. doi: 10.1016/S0145-2126(02) 00343-0

Kleine-Tebbe, J., Erdmann, S., Knol, E. F., MacGlashan, D. W. Jr., Poulsen, L. K., and Gibbs, B. F. (2006). Diagnostic tests based on human basophils: potentials, pitfalls and perspectives. Int. Arch. Allergy Immunol. 141, 79-90. doi: 10.1159/ 000094495

Ma, J. S., Kim, W. J., Kim, J. J., Kim, T. J., Ye, S. K., Song, M. D., et al. (2010). Gold nanoparticles attenuate LPS-induced NO production through the inhibition of NF-kappaB and IFN-beta/STAT1 pathways in RAW264.7 cells. Nitric Oxide 23, 214-219. doi: 10.1016/j.niox.2010. 06.005

Matsubara, S., Li, G., Takeda, K., Loader, J. E., Pine, P., Masuda, E. S., et al. (2006). Inhibition of spleen tyrosine kinase prevents mast cell activation 
and airway hyperresponsiveness. Am. J. Respir. Crit. Care Med. 173, 56-63. doi: $10.1164 / \mathrm{rccm} .200503-361 \mathrm{OC}$

Oliver, J. M., Burg, D. L., Wilson, B. S., McLaughlin, J. L., and Geahlen, R. L. (1994). Inhibition of mast cell Fc epsilon R1-mediated signaling and effector function by the Syk-selective inhibitor, piceatannol. J. Biol. Chem. 269, 29697-29703.

Ono, E., Taniguchi, M., Higashi, N., Mita, H., Kajiwara, K., Yamaguchi, H., et al. (2010). CD203c expression on human basophils is associated with asthma exacerbation. J. Allergy Clin. Immunol. 125, 483-489. doi: 10.1016/j.jaci.2009. 10.074

Pissuwan, D., Niidome, T., and Cortie, M. B. (2011). The forthcoming applications of gold nanoparticles in drug and gene delivery systems. J. Control Release 149, 65-71. doi: 10.1016/j.jconrel.2009.12.006

Plath, K. E., Grabbe, J., and Gibbs, B. F. (2003). Calcineurin antagonists differentially affect mediator secretion, p38 mitogen-activated protein kinase and extracellular signal-regulated kinases from immunologically activated human basophils. Clin. Exp. Allergy 33, 342-350. doi: 10.1046/j.1365-2222. 2003.01610.x

Rossi, A. B., Herlaar, E., Braselmann, S., Huynh, S., Taylor, V., Frances, R., et al. (2006). Identification of the syk kinase inhibitor R112 by a human mast cell screen. J. Allergy Clin. Immunol. 118, 749-755. doi: 10.1016/j.jaci.2006.05.023

Shore, P. A., Burkhalter, A., and Cohn, V. H. (1959). A method for the fluorometric assay of histamine in tissues. J. Pharmacol. Exp. Ther. 127, 182-186.

Sumbayev, V. V., Yasinska, I. M., Garcia, C. P., Gilliland, D., Lall, G. S., Gibbs, B. F., et al. (2013). Gold nanoparticles downregulate interleukin$1 \beta$-induced pro-inflammatory responses. Small 9, 472-477. doi: 10.1002/smll. 201201528
Varricchi, G., Raap, U., Rivellese, F., Marone, G., and Gibbs, B. F. (2018). Human mast cells and basophils - how are they similar how are they different? Immunol. Rev. 282, 8-34. doi: 10.1111/imr.12627

Wang, C., Liu, J., Wang, L., and Geng, X. (2008). Solubilization and refolding with simultaneous purification of recombinant human stem cell factor. Appl. Biochem. Biotechnol. 144, 181-189. doi: 10.1007/s12010-007-8112-0

Yasinska, I. M., Ceccone, G., Ojea-Jimenez, I., Ponti, J., Hussain, R., Siligardi, G., et al. (2018). Highly specific targeting of human acute myeloid leukaemia cells using pharmacologically active nanoconjugates. Nanoscale $10,5827-5833$. doi: 10.1039/c7nr09436a

Zuberbier, T., Chong, S. U., Grunow, K., Guhl, S., Welker, P., Grassberger, M., et al. (2001). The ascomycin macrolactam pimecrolimus (Elidel, SDZ ASM 981 ) is a potent inhibitor of mediator release from human dermal mast cells and peripheral blood basophils. J. Allergy Clin. Immunol. 108, 275-280. doi: $10.1067 /$ mai.2001.116865

Conflict of Interest Statement: The authors declare that the research was conducted in the absence of any commercial or financial relationships that could be construed as a potential conflict of interest.

Copyright $(2019$ Yasinska, Calzolai, Raap, Hussain, Siligardi, Sumbayev and Gibbs. This is an open-access article distributed under the terms of the Creative Commons Attribution License (CC BY). The use, distribution or reproduction in other forums is permitted, provided the original author(s) and the copyright owner(s) are credited and that the original publication in this journal is cited, in accordance with accepted academic practice. No use, distribution or reproduction is permitted which does not comply with these terms. 